\title{
Usage of E-Payment on Bus Rapid Transit (BRT): An Empirical Test, Public Acceptance and Policy Implications in Lagos, Nigeria
}

\author{
Richard Oluwole Alademomi *, Olayemi Hafeez Rufai, Emmanuel Tetteh Teye, \\ Kenneth Khavwandiza Sunguh, Helen Agbornso Ashu \\ University of Science and Technology of China \\ School of Public Affairs \\ Department of Public Administration \\ Hefei, Anhui 230026, China. \\ Victoria Omoladun Oludu \\ Hefei University of Technology \\ School of Management \\ Department of Business Administration \\ Hefei, China \\ Catherine Wanjiru Mbugua \\ University of Science and Technology of China \\ School of Managements \\ Department of Business Administration \\ Hefei, Anhui 230026, China
}

\begin{abstract}
Despite the fact that, electronic payment system has received so much attention from various researchers around the globe; in practice, there is still lack of acceptance in electronic payment system among the users in most developing economies considering its convenience and usefulness. Trust has been proposed as a crucial determinant for human decision on acceptance, yet just a couple of studies have investigated its role on electronic payment system. The major focus of this research was to test the role of trust as a mediator factor in determining acceptance of electronic payment in BRT system. Drawing on technology acceptance model (TAM) and the theory of planned behavior propounded by (Buckley et al. 2018), we empirically test the effectiveness of trust as a mediator using 356 survey data and verify the validity and reliability to provide evidence on the proposed hypothesis in this study through structural equation modeling (LISREL). The result indicated strong support for the effects of perceived security and perceived ease of use while perceived usefulness did not find support on the outcome. Most importantly, trust was found to significantly influenced acceptance of electronic payment system. The research findings suggest a positive means to encourage acceptance of electronic payment system for BRT users.
\end{abstract}

Keywords: Bus rapid transit (BRT), Technology acceptance model (TAM), Trust, Electronic payment, Structural equation model (SEM)

\section{Introduction}

Propelled by the growing mobility of today's contemporary society as result of increase in urban migration, the acceptance of electronic payment system has been on a tremendous increase in recent years (Ooi \& Tan, 2016). In compliance with this development, electronic payment services has increasingly turned into daily activities in human life (Hu, Huang, Zhong, Davison, \& Zhao, 2016), unlike previous traditional payment which was confined to either physical exchange of notes or coins (Di Pietro, Guglielmetti Mugion, Mattia, Renzi, \& Toni, 2015).The rapid growth in electronic payment technologies has created different payments opportunities for users today to explore various means of payments. Electronic payment system is a method of payments and transaction that occurs between two individuals in a swift, convenient, reliable and uncomplicated way or where goods and services are traded without the use of physical cash (Su, Wang, \& Yan, 2018). 
The benefits of this payment system to users of Bus Rapid Transit (BRT) and the companies entails greater flexibility of payment methods in business transactions, encouraging acceptance of this technology, greater convenience and time saving for the customers and the management of the system (Ming- Yen Teoh, Choy Chong, Lin, \& Wei Chua, 2013).

Bus Rapid Transit (BRT) is a contemporary breed of urban passenger transportation with frequently growing universal importance due to evidence of an ability to implement mass transportation capacity quickly and at a low moderate cost (Coninck, 2013). Habitually, more than 70\% population of Lagos state depends mostly on public transport system in order to meet up with their daily activities considering the traffic congestion in the city. Despite the fact that electronic means of payment is convenient, 'an average number of commuters still find it difficult to trust the technology considering the technological innovation and convenience in terms of payment' (Di Pietro et al., 2015). An average user of electronic payment in Lagos BRT finds it difficult to trust the security, usefulness and ease of use of the card. The trust people have in the efficiency and simplicity of electronic payment system will predict behavior of user attitude either to accept or reject the new technology (Baganzi \& Lau, 2017). The acceptance of electronic card payment is largely affected by users initial experience and their attitude towards new technological innovation (Di Pietro et al., 2015), even though electronic payment system has gained popularity in most financial transactions across the globe (Ramos-de-Luna, Montoro-Ríos, \& Liébana-Cabanillas, 2016). Adopter perception of usefulness of electronic means of payment may affect their decision to make payments through electronic means (Ooi \& Tan, 2016). Perceived usefulness stands for the utility value users thinks it derived from using a particular technology. Moreover electronic means of payment has to be developed to provide more easy access to BRT users in the process of payment in other to achieve socio economic policy. Considering the difficulties users encounter during the payment process through electronic card, users have to swap the card twice in the reader before the transaction is completed. Electronic card user awareness of ease of use behavior could be influenced by the access speed, convenience, portability and user friendliness (Ooi \& Tan, 2016). Hence the most significant factors in the ease of use in human perception includes effortless, easy to handle and simple (Buckley, Kaye, \& Pradhan, 2018). The complexity in any innovation technology might discourage users in accepting the technology considering the age and level of education of the adopters (Liébana-Cabanillas, Muñoz-Leiva, \& Sánchez-Fernández, 2018), the technology has to be user friendly and easily accessed for the adopters.

Significant research efforts have been centered on consumer adoption of goods and services, neglecting electronic payment research which serves as one of the key factors in the payment system (Yang, S. et al.2012). Lately, the payment system traditionally used in the BRT have been altered by the appearance of electronic card technology(Liébana-Cabanillas, Marinkovic, Ramos de Luna, \& Kalinic, 2018), mobile payment is considered by many researchers as one of the applications with the greatest prospective in the business sector (Liébana-Cabanillas, Marinkovic, et al., 2018). Cash transactions are considered to require huge cost of printing new notes and destroying mutilated ones, but the evolution of the electronic card payment system reduces existence of note money and thereby leads to economic gains for the government (Tan \& Tan, 2012). Researchers have shown little knowledge of the major drivers in consumer adoption of electronic payment services; they concentrated more on the consumer acceptance of goods and services(Oliveira, Thomas, Baptista, \& Campos, 2016).

This study aims at identifying various mechanisms that encourage commuters to embrace electronic money policy initiated by government and possible addition to improve acceptability of the technology. Moreover, it will also look at various reasons that discourage commuters from accepting electronic money policy initiated by the government considering the convenience and the economic value of the technology, the average commuters still finds it difficult to rely on the electronic payment technology. For this reason, data was collected from a representative sample of 356 respondents and structural equation model was adopted to test the hypothesis.

\section{Theoretical Background}

In the electronic payment system, varieties of theories have been adopted to explain innovation usage. This paper will adopt the theory of planned behavior propounded by Buckley, it was developed to better understand relationships that exist between attitude, intention and behavior of users (Buckley et al., 2018).

According to Trafimow (2009), it was assume that the following constructs are likely to change behavior of users towards a technology, they includes; intention, anticipated outcome, social normative, self efficacy and environmental constraints. It was also proposed that the direct path from perceived behavioral control to behavior has been identified as habit strength which has been found to be one of the strongest determinant of behavior and intentions (Pavlou \& Chai, 2002). Behavior can be directly envisaged from the intention to act (Oliveira et al., 2016) also noted that utilizing other terms and concept such as apathy, resistance and uncertainty, since what leads people to accept and support a technology is their attitudes and behavior. 
Also, it analyzed the evaluative influence associated to the prediction of the behavioral intention to use a technology by the users. According to (Trafimow, 2009), he assume the following construct like to change behavior of users towards a technology includes; intention, anticipated outcome, social normative, self efficacy and environmental constraints. Behavior can be directly envisaged from the intention to act. Zhang, Weng, \& Zhu (2018) also proposed that utilizing other terms and concept such as apathy, resistance and uncertainty, since what leads people to accept and support a technology is their attitudes and behavior, therefore, there is need for government to introduce more policies that will improve acceptance of electronic payment system.

\section{Literature Review}

It is obvious that the drivers of acceptance of electronic payment system in a survey-based study, (Paper, Mobile, View, View, \& Pousttchi, 2014) requested from the consumers which features of mobile payment applications they recognized as particularly pertinent? The authors present an analysis of frequency ranging that consumers prefer simple, secure and inexpensive payment services. The fact that technology innovation comprises of numerous advantage, lack of trust in the technology can affect the users' behavior (Bo, Huan, Meizi, Qin, \&Jifeng, 2017). Trust in electronic system of payment depends on the amount of the users perceived security, control, reliability and reputation of management in charge of the system (Duane A. et al. 2014). Relying on the past researchers, electronic payment has encouraged intention for online payments in china (Yang et al. 2015). Moreover, electronic payment device have the element of deceit, betrayal and lack of accountability due to its risk characteristics (Su et al., 2018).

Some other studies have gone further in considering the user demand of electronic money perspective and considered it a critical determinant for the success of electronic money patronage approach, deeming it useful for the sake of promoting user technology acceptance and innovation adoption (Oliveira et al., 2016).

A lot of researchers had carried out more on accessing the perspectives on electronic services. This has urged them to increase the quality, adaptation and usability of electronic money in payment for goods and services, which has created a lot of interest on the side of the researchers to access and evaluate the strategy of developing electronic money service and applications (Ramos-de-Luna et al., 2016).

The growth experienced in the world population at large today has directly have a negative impact on the transportation sector, this has caused citizens to demand from their government an affordable and easy movement from where they live to where they work or spend their leisure time. Electronic payment system has become a popular method of exchanging quick data between two devices, readers and other electronics tags(Ming- Yen Teoh et al., 2013). Generally, these attributes are known to influence people to accept electronic payment system; age, income, sex (Cao et al., 2009). Some authors also state that making provision for self service technology can increase acceptance of that technology (Ramos-de-Luna et al., 2016). Users prefer to have direct access to services without interaction with the provider of the technology. An average research studies has focused more on factors that encouraged the intention to adopt an electronic payment technology and finding the extent to which this factors affect intention to use the technology, a very good examples is the age of a potential user of a technology will influence his technological behavior (Liébana-Cabanillas, Marinkovic, et al., 2018). It has also been established by previous studies that a younger users are more likely to accept new innovation technologies than the old system (Liébana-Cabanillas, Muñoz-Leiva, et al., 2018). Previous research has indicated that acceptance of electronic card technology is affected by security concerns and risk; it is possible customers consider the security aspect of electronic card before accepting the technology (Su et al., 2018). It measures the belief of uncertainty about possible negative consequences (Zhang et al., 2018). Perceived risk has been discovered by the past studies as the significant factor contributing or influencing acceptance intention towards electronic payment system (Straub, 2003). However user's behavior cannot be easily predicted, so there is need for additional studies on electronic payments behavior (Kim et al., 2010).

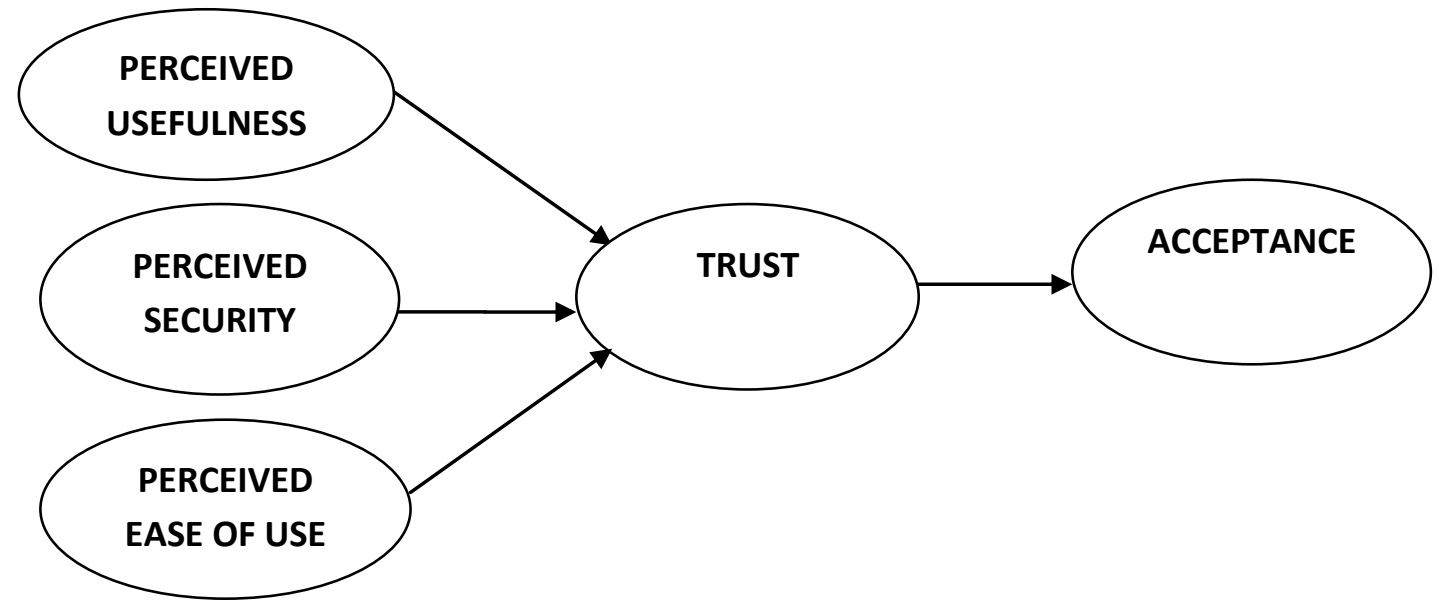


Figure 1: Research Model: P. G. Schierz et al. (2010): Electronic Commerce Research and Applications vol. 9 (209-21) This model is designed to measure acceptance of electronic money in BRT according to this three independent variables; namely, perceived security, perceived usefulness and perceived ease of use. The three independent variables have indicators that can be used to measure acceptance of electronic money, with this model, we can link the relationship between this three variables to determine acceptance with trust acting as a mediator between them. Moreover, these variables were selected because of their flexibility and application for measuring the acceptance of electronic money.

\section{Methodology}

The study aims and objectives are to define more factors that can contribute to user's adoption of electronic payment in Lagos state BRT system. The information required for this study was not available in the form of secondary data, so we collected primary data through a survey. A proportionate stratified sampling and simple random sampling approach was used. The goal was to generate a sample that is representative of the total population in terms of gender, age, and income.

A questionnaire base survey was conducted using simple random sampling approach. The data was collected through online survey by randomly selecting Nigerians who live in Lagos city, by Google Docs tool (Table 1) particularly between Ikorodu and CMS Local Government Areas boarding stations to validate the research model. Ikorodu and CMS were chosen because the usages of electronic payment system only function in these routes for now; it was introduced in the route late 2014 by the past administration to further encourage users. Also the sampling location is a major hearth of businesses and economic location of the state. The survey was conducted using a standardized online questionnaire, which was subjected to comprehensive pretesting prior to implementation. This was proofread by two academic scholars in University of Lagos to ascertain the suitability of the questions and measurement in the questionnaire. After that, a pilot study was conducted with 50 respondents so as to show how the responses correspond to the research objectives and questions. At the end of the data collection period, a final analysis was conducted using 356 responses out of a total of 400 which is equivalent to $89 \%$ responses. The research adopts Structural Equation Modeling by using LISREL 8.7 to analyze the data.

There were three independent variables for this study.

Perceived security: This can be refered to as the trust people have in the security of a technology wheather to accept it or not (Bo et al., 2017). Perceieved security is the perception against the risk related with electronic payment system, the notion perceived by the user loosing their money stored electronically in the card which may result in financial loss (Ooi \& Tan, 2016). The users perceived security was evaluated with measurement items such as "I feel secured whenever am using electronic payment with my card (Abdullah et al., 2010)

Perceived usefulness: This refers to relative advantage and entrinsic motivation of users to adopt electronic payment (Su et al., 2018). An average users of a new technology will question him or herself the versartilityof that technology. Perceived usefulness is always considered by any potential adoptal when considering acceptance of a new innovation technology. (Ooi \& Tan, 2016) also found out that electronic money perceived usefulness leads to higher intention to adopt an electronic payment system. The perceived usefulness was evaluated with measurement items such as "I think that electronic payment takes less time (Di Pietro et al., 2015)".

Perceived ease of use : Perceived ease of use can be considered as a significant driver behind acceptance of any technological innovation. One of the two key variables in the technology acceptance model is perceived ease of use, Perceived ease of use will lead to attitude toward use. It is the degree to which a person believes that using a particular system would be free of effort. According to (Su et al., 2018), he emphasized that friendly connections, operation and function in protecting hihger users acceptance. The perceived ease of use was also evaluated with measurement items such as "I think electronic payment is easy to use (Di Pietro et al., 2015)".

\section{Hypothesis}

H1: There is positive and direct relationship between trust and acceptance.

Trust is acting as an essential factor of building a successful relationship between perceived security, perceived usefulness and ease of use. An average user of electronic card often seek information from peer group to determined if a technology can be trusted (Smith et al. 2011). The fact that a technology is perceived to be easy to operate does not relegate trust (Buckley et al., 2018). Trust has been acting as a catalyst for adopters and managers transactional relationship to last long. Users trust in an electronic payment system cannot be under estimated as there is no trait that a user will continue to adopt a technology with unethical, undesirable and opportunistic behavior from the manager. "A user will prefer to trust an unsecure payment system from trusted company than a secured payment system from an untrusted company" (Verkijika, 2018), he believes that trust is more valuable compared to security. 
Trust act as the determinant of acceptance of any technological innovation, it has a vital role to play in any financial transaction relationship where risk is involved. The trust in electronic payment services refers to structural assurance (Zhou, T. 2014). Structural assurance enables to reduce electronic money user perceived risk in adopting the technology. The trustworthiness refers to perception that the electronic service provider possesses the integrity, competence and benevolence required (Park, J.-K et al. 2012). Integrity here means the managers reflects the picture of who they are and sticks to their promises. Competence on the other hand refers to the manager's possession of required experience and understanding to accomplish the tasks and benevolence means the managers are more concern to the user's interest not focusing on profit maximization alone (Di Pietro et al., 2015).

For the fact that technological innovation may have numerous benefits, lack of trust in the technology may affect its use (Verkijika, 2018).Trust has a vital role in financial exchange relationships where there are unknown risk, if the management show benevolence, competence and integrity, users are more likely to accept electronic card for payments (Leong et al. 2013). (Aljukhadar, Trifts, \& Senecal, 2017) "state that customer satisfaction is a broad concept that includes perceived evaluation of products and services" the level of trust that developed between company and customers has been described as a "fundamental relationship building block" (Ring, 1996) the more the customer trust in the company, the higher the perceived value of the relationship by the customer (Walter et al. 2002); moreover, it is expected that the greater the chances will be that the customer remain in the relationship. (Gounaris, 2005) trust is an important element of the perceived quality of service. According to (Morgan and Hunt, 1994) trust has been conceptualized as the self assurance that the relationship collaborators have developed reliability and integrity between them. Hog berg (2002) suggests that trust develops successively; it is as a result of deepening of the relationship through a process of mutual adaptation to the needs of the other party, although not necessarily symmetrically. Trust is envisaged as the confidence of the parties involved in the goodwill of each other on which the parties depend. Ring (1986) sees trust as the strong belief in a partner's selflessness and in the moral order of the relationship, this judgment leads to integrative behavior which eventually extended the duration of the relationship (Ganesan, 1994).

H2: There is a positive relationship between perceived security and trust to influence acceptability of electronic money.

The trust consumers has in electronic money security will encourage them to adopt the technology. Perceived security refers to perception against the risk related with electronic payment system, most especially the perception of losing money stored electronically in the card which could in turn resulted in financial losses (Ooi \& Tan, 2016). Feeling secured during financial transaction with electronic payment technology is a major concern to average users, it is important for the managers of the cards to minimize concerns regarding the use of the technology to make payment. Therefore perceived innovation technology security will rely on trust before it could be accepted. It is noted as one of the reasons why perceived security is considered as a core influence in acceptance of electronic payment technology. Users need to be assured that the security of a technology is guaranteed to encourage acceptance. A lot of researchers has emphasized that adoption of technology could be negatively influenced because of the insecurity in the services (Ooi \& Tan, 2016). It was also suggested by (Oliveira et al., 2016) that the security needs to be guarantee in other for the users to feel secured while using electronic payment system. Acceptance of electronic card technology is affected by security concerns and risk, it is possible customers considered the security aspect of electronic card before accepting the technology (Ramos-de-Luna et al., 2016). Risk assessment and safety are one of the major obstacles in electronic payment system (Schierz, Schilke, \& Wirtz, 2010). Security is very important in electronic payment system to ensure users interest are protected and guarantee for them to have confidence in the managers to encourage acceptance. The perception of electronic payment safety must be regulated for the technology to be successful (Schierz et al., 2010).Therefore, assurance of security of electronic payment system by the managers is one of the preconditions that determines acceptance of the new technology, it measures the belief of uncertainty about possible negative consequences (Ming- Yen Teoh et al., 2013). The level of uncertainty in the electronic payment system today has made the system more ambiguous and uncomfortable (Pavlou \& Chai, 2002), this is associated with users perception of security regarding adoption of electronic payment system (Ming- Yen Teoh et al., 2013). An average user may not trust the security of the reader in the BRT which sometimes malfunction due to the system inability to read the card successfully. Perceived security has been discovered by the past studies as the significant factors contributing or influencing acceptance intention towards electronic payment system (Liébana-Cabanillas, Marinkovic, et al., 2018). Electronic card information needs to be configured correctly by managers to avoid any misuse or attacks. The administration organization needs to ensure solid equity and trust to the users in order to boost the relationship between them. The service quality is referring to the assistance Lagos state government is putting in place to aid the management in providing reliable and quality electronic cards to the users.

H3: Perceived usefulness is positively related to trust to enhance electronic money acceptance.

Electronic card usefulness is similar to sub-constructs of usefulness such as relative advantage and extrinsic motivation and elaborates how they lead to acceptance for a particular individual (Ooi \& Tan, 2016). 
Usefulness is always considered for any potential adopter when accepting electronic devices. (Liébana-Cabanillas, Muñoz-Leiva, et al., 2018) found out that electronic usefulness leads to higher intention to accept electronic payment system. Users perception of usefulness of electronic payment system may affect their decisions to make payment through electronic means while making payment (Schierz et al., 2010) It was also discovered by a study that electronic means of payment usefulness leads to higher intention to use (Tan \& Tan, 2012) and similar study was also carried out by (Su et al., 2018) which implies that adoption of electronic payment system brings about time saving, convenience and portability. Considering the technical limitations of electronic money, trust becomes an impending driver of technological usefulness to be accepted (Chandra, 2010). Perception of usefulness is also refers to as perceptions of performance probability (Bo et al., 2017). This described the level at which users sees the importance and usefulness of an innovation technology before they consider acceptance. Trust in the perceived usefulness plays a sensitive role in determining user's intention to adopt electronic payment system. Naturally, an average users believe in finding out about unknown situations by listening to other users experience and comments in terms of usefulness of the technology (Su et al., 2018), the information from this reference group concerning the usefulness can encourage potential user to accept the new technology (Ming- Yen Teoh et al., 2013). Perceived usefulness positive and significance effect on intention to adopt was stated in various studies. For example, (Liébana-Cabanillas, Muñoz-Leiva, et al., 2018) discovered perceived usefulness a significant determinant of intention to use electronic payments system. Perceived usefulness was found to be one of the strongest predictor of acceptance of electronic base payment system (Pham and Ho, 2015). The usefulness of a technology is paramount when users are taking into consideration adoption of a new technology. Also the perceived usefulness of electronic payment system is directly related to trustworthiness.

H4: Perceived ease of use is positively related to trust to allow acceptance of electronic money.

The study emphasized on the friendly connection, system operation and function in protecting higher users' acceptance. Tan et al. (2014a, b) findings shows that the intention to use is determined by perceived usefulness, perceived ease of use, social influence and personal innovativeness in information technology. Perceived ease of use can be considered as a significant driver behind acceptance of any technological innovation in the global village of today, any technology perceived to be too complex will attract low acceptability (Liébana-Cabanillas, Marinkovic, et al., 2018). Ease of use in any technology has to be considered as the most significant factor while considering possibility of acceptance in electronic payment system, A system that is complex to use will attract low level of perceived ease of use (Su et al., 2018). A technology has to be interactive and friendly, a perceived ease of use refers to the extent to which the prospective users expect electronic payment to be effortless (Chen 2008). It determines user's attitude and behavior towards a particular technology. Considering the technical limitations of electronic money, ease of use is believed to be an anticipated acceptance driver of mobile applications (Ming- Yen Teoh et al., 2013). The adoption of electronic payment system requires minimum effort to use; it does not require a complex education before user get use to the application. Users will more likely to adopt this new innovation without hesitation. Also, the technology acceptance model (TAM), by (Trafimow, 2009), is a modification of general theory of reasoned action(TRA) model by Fishbein and Ajzen (1975), specifically indicated to model of acceptance of information systems. The importance of these models (TAM and TRA) influenced the adoption of information technologies has been proven consistently (e.g., Davis 1989; Davis et al. 1989). TAM is considered the strongest and the most influential model in acceptance behaviors in various fields (Davis 1989; Davis et al. 1989). Complexity is defined as "the degree to which an innovation is perceived as relatively difficult to understand and use" innovation that are perceived to be easier to use are likely to be preferred and used by the potential users (Ooi \& Tan, 2016).

Table 1: Demographic information of the respondents

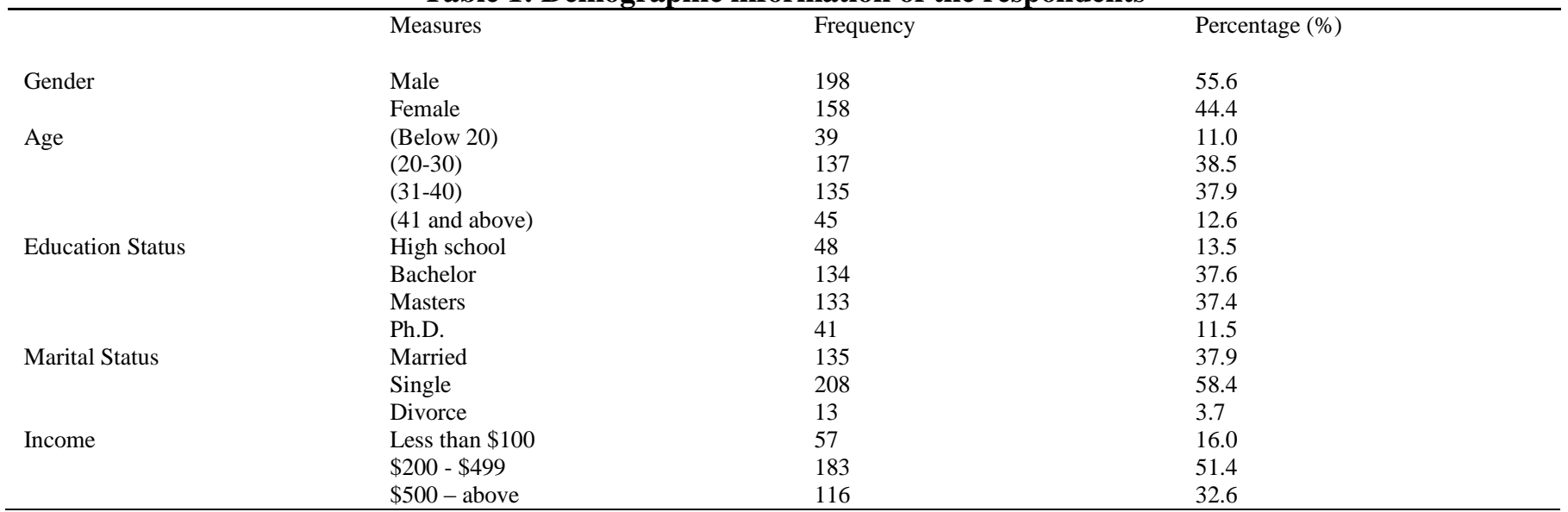


Structural equation modeling (SEM) was used to test the proposed theoretical model.

SEM is a widely used modeling technique applied in social sciences to understand and explain relationships among the elements of systems (Yi et al., 2006). SEM simultaneously estimates and assesses a series of hypothesized inter-related dependency relationships between a set of latent (and observed) constructs. The constructs are measured by one or more manifest (or observed) variables (Reisinger and Mavondo, 2007). An annex of SPSS popularly known as macro developed by Hayes (2013) was adopted to test the entire hypothesis (mention that spss was used for factor analysis EFA and SEM CFA was carried out using Lisrel 8.70).

\section{Measurement of Variables/ Estimation approach}

Measurement items were adapted from previous research studies with little modication of words and sentences in accordance with the current study. The measurement items for perceived security were adapted from the study of (Luarn \& Lin, 2005); perceived usefulness from (Odel, 2001); perceived ease of use was adapted from (Odel, 2001). The 5-point Likert scale was used with 1 indicating strongly agree, 3 indicating neutral, and 5 indicating strongly disagree to measure the responses.

To examine the latent variables within their causal structure, we applied structural equation modeling (SEM) using LISREL software. SEM approach was adopted as it is a powerful generalization of earlier statistical approaches with the key advantage being that each explanatory and dependent variable is associated with measurement error in disparity to OLS regression, for example, that is based on the assumption that variables are measured perfectly. In addition, SEM allows for multiple indicators of latent variables which are a more realistic representation of the variables under study.

\section{Table 2: Measurement Items}

The table below shows the various measurements used to measure the constructs.

\begin{tabular}{|c|c|c|}
\hline CONSTRUCT & ITEMS & REFRENCES \\
\hline Acceptance of e-money & $\begin{array}{l}\text { I am likely to adopt electronic payment in the near } \\
\text { future } \\
\text { If I am given the opportunity, I will use electronic } \\
\text { means while making my payment } \\
\text { I plan to use electronic payment whenever the } \\
\text { opportunity arises } \\
\text { I am open to using electronic payment in the } \\
\text { nearest future }\end{array}$ & Ramos de Luna et al. (2016) \\
\hline Trust in e-money & $\begin{array}{l}\text { I trust on the e-payment that will not lead to } \\
\text { transaction fraud } \\
\text { My confidential information is delivered safely } \\
\text { while using e-payment } \\
\text { I feel the risk involved in e-payment is low } \\
\text { I trust on the ability of an e-payment system to } \\
\text { protect my privacy }\end{array}$ & (Kim, Mirusmonov, \& Lee, 2013) \\
\hline Perceived security & $\begin{array}{l}\text { The risk of losing billing information (e.g } \\
\text { electronic card number ) to the third party is low } \\
\text { when making electronic payment } \\
\text { The risk of an unapproved party involving in the } \\
\text { payment process is low. } \\
\text { The risk of losing personal information to the third } \\
\text { party is low }\end{array}$ & (Luarn \& Lin, 2005) \\
\hline Perceived usefulness & $\begin{array}{l}\text { Electronic means of payment is useful in making } \\
\text { payment } \\
\text { It is more advantageous to use electronic payment } \\
\text { Using electronic card payment makes the handling } \\
\text { of payment easier } \\
\text { Payment is faster when using electronic payment }\end{array}$ & (Odel, 2001) \\
\hline Perceived ease of use & $\begin{array}{l}\text { I find it easy using electronic payment } \\
\text { My interaction with electronic payment are } \\
\text { unambiguous and straight forward } \\
\text { The steps in electronic payment are very easy to } \\
\text { follow } \\
\text { It is easy to communicate with electronic payment } \\
\text { system }\end{array}$ & (Odel, 2001) \\
\hline
\end{tabular}

\section{Results}




\section{Step 1}

The data was analyzed by using structural equation modeling (SEM) and LISREL 8.70 was deployed to analyze and measure the structural model. The study also used exploratory factor analysis to divide out the dimension reduction of items. To test the validity of the data, reliability test was run. However, researchers had utilized an incredible instrument that uses the confirmatory factor analysis, regression and structural model simultaneously to access measurement model (Elangovan \& Rajendran, 2015). The threshold level for cronbach's alpha, composite reliability and average variance extracted (AVE) was $0.7,0.7$ and 0.5 respectively, according to the standard criteria in existing literature (Fornell, Larcker, Perreault, \& Anderson, 1988). As exhibited in Table 3, composite reliability and cronbach's alpha values are more than 0.7 and AVE values for all constructs were greater than .5 , uncovering great convergent validity. (Fornell et al., 1988) stated that, another approach to decide discriminate validity is to compare the relationship between correlation amid the constructs and the square root of AVE of all constructs. In the event that AVE square root is greater than the correlation among construct, this demonstrates great discriminate validity.

\section{Step 2}

SEM as a interdisciplinary research tool has now turned out to be one of the essential systems utilized by researcher to validate their research results (Hooper, Coughlan, \& Mullen, 2008). To assess the model fitness, researchers needs to inspect the model fitness indices, for example, root mean square root error of approximation (RMSEA), Chi - square, adjusted goodness of fit index (AGFI), goodness of fit index (GFI) Tucker - Lewis index (TLI) and comparative fit index (CFI). As indicated by the previous studies, for model goodness, the obtainable value of chi-square value must not be less than 2.0 and not greater than 5.0, base on the sample size (Barrett, 2007). The obtainable value for RMSEA ought to be under 0.10 (Hooper, Coughlan, \& Mullen, n.d.) and as indicated by (Fornell et al., 1988) the maximum limit is 0.7 and it ought to be less than 0.08 (Mcquitty \& Wolf, 2015). As stated by (Fornell et al., 1988), GFI and AGFI indices values can be greater than 0.90 and 0.80 respectively. Different researchers prescribed that for NFI, IFI and CFI indices, the values can be more than 0.85 (Barrett, 2007), for the sake of this study, SEM techniques was adopted along with LISREL 8.70 and confirmatory analysis to measure the model goodness of fit utilizing indices. According to the previous recommendations, indices intended for the study indicated the suitable goodness of fit for measurement and structural model where all estimation of chi-square, RMSEA, IFI, NFI, TLI, CFI, AGFI and GFI are within adequate rage as appeared in Tables 3 and 4.

Subsequent step is to test the hypothesis relationship. As indicated by the results, the significant path coefficient seems to support the proposed model. With the help of $\mathrm{H} 1$, we discovered a significant and positive relationship between perceived security and trust towards the acceptance of electronic payment $(b=0.064 ; p<.01)$.

Conversely, the path coefficient of 0.7 , significant at a $1 \%$ level, indicates a strong negative relationship between perceived usefulness of electronic payment and trust in e-money. That is, in spite of the usefulness of electronic payment, users may not be comfortable using it probably as a result of other factors not associated with acceptance.

Table 3: Confirmatory Factor Analysis (CFA)

\begin{tabular}{llllll}
\hline Constructs & & Factor loading & Cronbach Alpha & AVE & CR \\
\hline Perceived Security & PSI & 0.818 & 0.914 & 0.731 & 0.891 \\
& PS2 & 0.857 & & & \\
& PS3 & 0.889 & 0.803 & 0.507 & 0.801 \\
Perceived usefulness & PU1 & 0.751 & & & \\
& PU2 & 0.650 & & & \\
& PU3 & 0.599 & 0.886 & 0.647 & 0.880 \\
Ease of Use & PU4 & 0.841 & & & \\
& EU1 & 0.775 & & & \\
E-Money & EU2 & 0.804 & 0.904 & 0.685 & \\
& EU3 & 0.790 & & & \\
& EU4 & 0.846 & & & \\
EM1 & 0.862 & & \\
Acceptance & EM2 & 0.834 & 0.639 & \\
& EM3 & 0.837 & & & \\
& EM4 & 0,776 & & & \\
& A1 & 0.805 & & & \\
& A2 & 0.746 & & & \\
& A3 & 0.841 & & & \\
\hline
\end{tabular}


Extraction Method: Maximum Likelihood. Rotation Method: Promax with Kaiser Normalization

In addition, the structural link from perceived ease of use and trust in electronic money is positive and significant $(b=$ $.18 ; \mathrm{p}<.01$ ), thereby leading to acceptance of electronic payment and supporting $\mathrm{H} 3$. The results from the reliability tests strongly suggest that the correlations between the exogenous variables do not compromise the validity of our results.

Table 4: Means, standard deviations, correlations, and AVE Square-root

\begin{tabular}{llllllll}
\hline Constructs & Mean & $(\mathrm{SD})$ & PS & PU & EU & EM & A \\
\hline PS & 1.76 & $(0.747)$ & $\mathbf{0 . 8 5 5}$ & & & & \\
PU & 1.66 & $(0.497)$ & .331 & $\mathbf{0 . 7 1 2}$ & & & \\
EU & 1.55 & $(0.530)$ & .492 & .448 & $\mathbf{0 . 8 0 4}$ & & \\
EM & 1.71 & $(0.712)$ & .656 & .220 & .435 & $\mathbf{0 . 8 2 8}$ & \\
A & 1.52 & $(0.568)$ & .383 & .309 & .369 & .402 & $\mathbf{0 . 7 9 9}$ \\
\hline
\end{tabular}

Note. $\mathrm{N}=356$. All correlations are significant at $\mathrm{p}<0.001$. Values on the diagonal represent average variance extracted (AVE).

Table 5: Measurement Model

\begin{tabular}{lllllllll}
\hline Fit indices & $\mathrm{x}^{2} / \mathrm{df}$ & RMSEA & GFI & AGFI & CFI & NFI & NNFI & IFI \\
\hline Recommended value & $<3$ & $<0.08$ & $>0.90$ & $>0.80$ & $>0.90$ & $>0.90$ & $>0.90$ & $>0.90$ \\
Value in this study & 1.624 & 0.042 & 0.94 & 0.91 & 0.99 & 0.97 & 0.98 & 0.99 \\
\hline
\end{tabular}

Table 6: Structural Model

\begin{tabular}{lllllllll}
\hline Fit indices & $\mathrm{x}^{2} / \mathrm{df}$ & RMSEA & GFI & AGFI & CFI & NFI & NNFI & IFI \\
\hline Recommended value & $<3$ & $<0.08$ & $>0.90$ & $>0.80$ & $>0.90$ & $>0.90$ & $>0.90$ & $>0.90$ \\
Value in this study & 1.746 & 0.046 & 0.93 & 0.91 & 0.99 & 0.97 & 0.98 & 0.99 \\
\hline
\end{tabular}

After having gained confidence about the appropriateness of the measurement, the next step was to examine the structural model. The goodness of fit measures for the structural model show satisfactory values $\left(\mathrm{x}^{2} / \mathrm{df}=1.746\right.$; GFI $=.93 ; \mathrm{AGFI}=.91 ; \mathrm{TLI}=.82 ; \mathrm{RMSEA}=.046)$.

For all datasets, the pattern of results is consistent with our hypotheses except the relationship between perceived usefulness and acceptance of electronic payment because of its negative relationship. Therefore, all hypothesized relationships were supported in the samples, which further underline the strength of our results. Finally, we evaluated the issue of multicollinearity by looking at the immensity of the bivariate correlations between the exogenous variables as shown in Table 4. Together with the results obtained from the stability tests, this indicates that multicollinearity is not a problem in our research study.

\section{Discussion}

The primary theme of this study was to examine the impact of acceptance of electronic payment usage in BRT system by considering the security influence, ease of use and the usefulness of the technology. The electronic payment is an important driving force for further revolution and transformation of the economic activities. Therefore, promoting the technology is the key to structural reforms in the transportation industry which can motivate the country market at a deeper level to achieve healthy and sustainable development. 


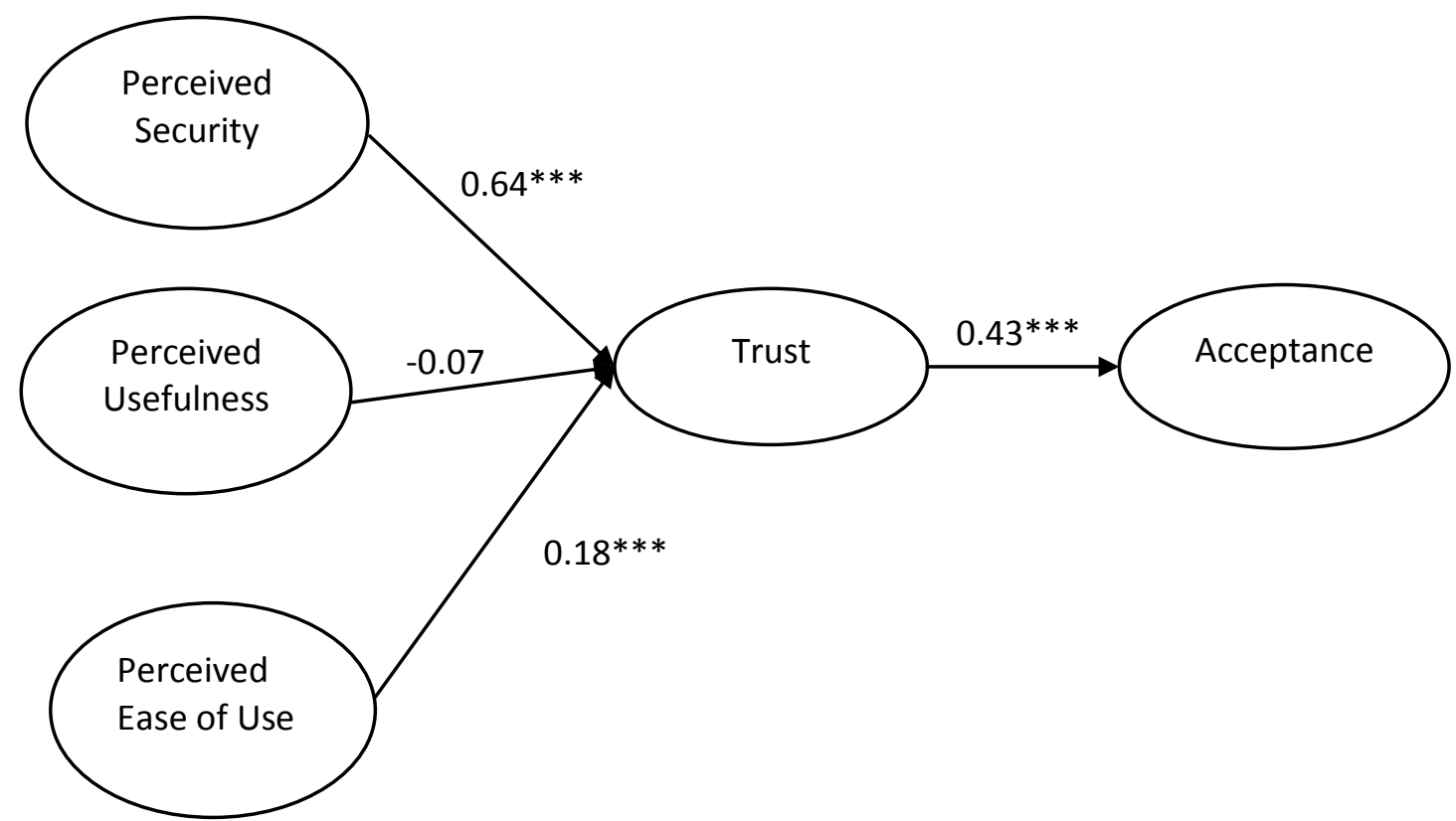

Figure 2: Path diagram $(* * \mathrm{p}<0.05 ; * * * \mathrm{p}<0.01)$

The technology can be promoted by providing favorable education and awareness creation to the users which enhances their intention toward e-payment. Researchers, policymakers, and educators should focus on creating awareness programs and should provide users with practical adequate information in order to orientate them to accept the technology.

The research findings show that trust significantly mediate perceived security and acceptance of e-payment technology. This brings about a positive significance impact on acceptance. Perceived usefulness on the other hand showed a negative non-significant impact on acceptance of e-payment system. This is as a result of the perception that despite the usefulness of the technology, it doesn't guarantee the trust of the users' attitude toward electronic payment. The perceived ease of use is found to be positively associated with acceptance of the technology and this promotes trust between the two variables.

This study is the first to investigate the impact of using trust to mediate the relationship between individual behavior (perceived security, perceived usefulness, perceived ease of use) and acceptance of e-payment. The study also provides some important contributions to the literature on electronic money by exploring the relationship between the perceived security, ease of use and usefulness and users acceptance of electronic payment technology. Electronic money is considered by many researchers as one of the applications with a pronounced potential in the society today (Ming- Yen Teoh et al., 2013). It has become a global means of making payment for transactions in the society today as a result of its convenience and simplicity. To encourage the e-payment utilization among the users, policy makers can adopt the incentive techniques by which users will be encouraged to consider e-payment usage instead of traditional payment method. This will promote sustainable and economic development in the transportation system in Nigeria.

\section{Conclusion and future research}

Electronic payment has become a global system, it is presently receiving attention from both user and the managers across the globe and this study contributed evidence about accepting electronic payment through examining factors related to acceptance, particularly in the BRT system. The study concludes that e-payment system is a useful, easy, and likeable way of carrying out transaction, which helps the users to reduce the burden of carrying cash for payment. There is a need to shift from traditional methods of payment (e.g., cash, ticketing) to smart card technology that help users to conveniently make payment (Hamad, Petri, Rezgui, \& Kwan, 2017). Although the perceived usefulness in the study reflected a negative impact on acceptance, nevertheless, it is paramount for government to introduce a more convenient way of payment to users in order to encourage acceptance of electronic payment system. Essentially, it is the duty of BRT operators to take feedback from the users regarding the perceived security, perceived usefulness and perceived ease of use in order to make modification appropriately. The challenges faced in the electronic payment system can be tackle by introducing more convenient method of payment electronically e.g. paying through a mobile phones. There are a lot of problems faced in the implementation of electronic payment system in Lagos BRT. In such manner, there is need for management of BRT to seek for more innovative ways to encourage acceptance of electronic payment system. 
An average user is always reluctant to accept new technological innovation but there is need for operators to create awareness program on usages of electronic payment, create reliable and trusted mode of payment electronically. Future research will focus more on what governmental policy can be implemented in designing more convenient means of electronic payment either by mobile phone applications (Whatsapp, Alipay, QQ, Wechat) to motivate users for acceptance.

\section{Acknowledgement}

Grateful thanks are accorded to Professor Song Wei, and his assistant Zhao Shu Liang for bestowing supportive comments on the previous draft of this paper. Warm regards to the Chinese Government Scholarship Council for giving the Author with fully funded scholarship to pursue his postgraduate studies at the University of Science and Technology of China (USTC).

\section{References}

Abdullah, F., Alani, F., Yaqoub, Y., Hamdan, M., Brady, M. K., Cronin, J. J. J., ... Parasuraman, A. (2010). A Study of Service Quality Determinants of Private Universities in Bangladesh using SERVQUAL. International Education Studies, 6(4), 86-95. https://doi.org/10.2307/1251929

Aljukhadar, M., Trifts, V., \& Senecal, S. (2017). Consumer self-construal and trust as determinants of the reactance to a recommender advice. Psychology and Marketing, 34(7), 708-719. https://doi.org/10.1002/mar.21017

Baganzi, R., \& Lau, A. K. W. (2017). Examining trust and risk in mobile money acceptance in Uganda. Sustainability (Switzerland), 9(12). https://doi.org/10.3390/su9122233

Barrett, P. (2007). Structural equation modelling : Adjudging model fit, 42, 815-824. https://doi.org/10.1016/j.paid.2006.09.018

Bo, Z., Huan, Z., Meizi, L., Qin, Z., \& Jifeng, H. (2017). Trust Traversal: A trust link detection scheme in social network. Computer Networks, 120, 105-125. https://doi.org/10.1016/j.comnet.2017.04.016

Buckley, L., Kaye, S. A., \& Pradhan, A. K. (2018). Psychosocial factors associated with intended use of automated vehicles: A simulated driving study. Accident Analysis and Prevention, 115(April), 202-208. https://doi.org/10.1016/j.aap.2018.03.021

Chandra, S. (2010). Evaluating the Role of Trust in Consumer Adoption of Mobile Payment Systems : An Empirical Analysis, 27(1).

Coninck, H. C. de. (2013). Climate technology \& development case study: Bus rapid transit, (February). Retrieved from http://climatestrategies.org/wp-content/uploads/2015/01/Climate-Technology-and-Development-Casestudy-Bus-Rapid-Transit-Heleen-de-Coninck-final.pdf

Di Pietro, L., Guglielmetti Mugion, R., Mattia, G., Renzi, M. F., \& Toni, M. (2015). The Integrated Model on Mobile Payment Acceptance (IMMPA): An empirical application to public transport. Transportation Research Part C: Emerging Technologies, 56, 463-479. https://doi.org/10.1016/j.trc.2015.05.001

Elangovan, N., \& Rajendran, R. (2015). Structural equation modeling-A second-generation multivariate analysis, (April). https://doi.org/10.13140/RG.2.1.4837.4885

Fornell, C., Larcker, D., Perreault, W., \& Anderson, C. (1988). Structural Equation Modeling in Practice : A Review and Recommended Two-Step Approach, 103(3), 411-423.

Gounaris, S. P. (2005). Trust and commitment influences on customer retention: Insights from business-to-business services. Journal of Business Research, 58(2 SPEC.ISS.), 126-140. https://doi.org/10.1016/S0148-2963(03)00122-X

Hamad, A. A. A., Petri, I., Rezgui, Y., \& Kwan, A. (2017). Towards the innovation of an integrated 'One-Stop-Shop' online services utility management: Exploring customer' technology acceptance. Sustainable Cities and Society, 34(June), 126-143. https://doi.org/10.1016/j.scs.2017.06.019

Hooper, D., Coughlan, J., \& Mullen, M. (n.d.). - Use Licence - Structural Equation Modelling: Guidelines for Determining Model Fit.

Hooper, D., Coughlan, J., \& Mullen, M. R. (2008). Structural Equation Modelling : Guidelines for Determining Model Fit, 6(1), 53-60.

Hu, X., Huang, Q., Zhong, X., Davison, R. M., \& Zhao, D. (2016). The influence of peer characteristics and technical features of a social shopping website on a consumer's purchase intention. International Journal of Information Management, 36(6), 1218-1230. https://doi.org/10.1016/j.ijinfomgt.2016.08.005

Kim, C., Mirusmonov, M., \& Lee, I. (2013). Computers in Human Behavior An empirical examination of factors influencing the intention to use mobile payment. Computers in Human Behavior, 26(3), 310-322. https://doi.org/10.1016/j.chb.2009.10.013 
Liébana-Cabanillas, F., Marinkovic, V., Ramos de Luna, I., \& Kalinic, Z. (2018). Predicting the determinants of mobile payment acceptance: A hybrid SEM-neural network approach. Technological Forecasting and Social Change, 129(December), 117-130. https://doi.org/10.1016/j.techfore.2017.12.015

Liébana-Cabanillas, F., Muñoz-Leiva, F., \& Sánchez-Fernández, J. (2018). A global approach to the analysis of user behavior in mobile payment systems in the new electronic environment. Service Business, 12(1), 25-64. https://doi.org/10.1007/s11628-017-0336-7

Luarn, P., \& Lin, H. (2005). Toward an understanding of the behavioral intention to use mobile banking, 21, 873-891. https://doi.org/10.1016/j.chb.2004.03.003

Mcquitty, S., \& Wolf, M. (2015). Structural Equation Modeling: A Practical Introduction . Structural Equation Modeling : A Practical Introduction, (April).

Ming- Yen Teoh, W., Choy Chong, S., Lin, B., \& Wei Chua, J. (2013). Factors affecting consumers' perception of electronic payment: an empirical analysis. Internet Research, 23(4), 465-485. https://doi.org/10.1108/IntR-092012-0199

Odel, C. O. M. (2001). U NDERSTANDING I NFORMATION S YSTEMS C ONTINUANCE: A N E XPECTATION -, 25(3), 351-370.

Oliveira, T., Thomas, M., Baptista, G., \& Campos, F. (2016). Mobile payment: Understanding the determinants of customer adoption and intention to recommend the technology. Computers in Human Behavior, 61(2016), 404-414. https://doi.org/10.1016/j.chb.2016.03.030

Ooi, K. B., \& Tan, G. W. H. (2016). Mobile technology acceptance model: An investigation using mobile users to explore smartphone credit card. Expert Systems with Applications, 59, 33-46. https://doi.org/10.1016/j.eswa.2016.04.015

Paper, C., Mobile, K., View, G., View, D., \& Pousttchi, K. (2014). Security issues in mobile payment from the customer viewpoint, (May).

Pavlou, P., \& Chai, L. (2002). What Drives Electronic Commerce across Cultures? A Cross-Cultural Empirical Investigation of the Theory of Planned Behavior. Jounal of Electronic Commerce Research, 3(4), 240-253. https://doi.org/10.1.1.144.1549

Ramos-de-Luna, I., Montoro-Ríos, F., \& Liébana-Cabanillas, F. (2016). Determinants of the intention to use NFC technology as a payment system: an acceptance model approach. Information Systems and E-Business Management, 14(2), 293-314. https://doi.org/10.1007/s10257-015-0284-5

Schierz, P. G., Schilke, O., \& Wirtz, B. W. (2010). Understanding consumer acceptance of mobile payment services: An empirical analysis. Electronic Commerce Research and Applications, 9(3), 209-216. https://doi.org/10.1016/j.elerap.2009.07.005

Su, P., Wang, L., \& Yan, J. (2018). How users' Internet experience affects the adoption of mobile payment: a mediation model. Technology Analysis and Strategic Management, 30(2), 186-197. https://doi.org/10.1080/09537325.2017.1297788

Tan, W. K., \& Tan, Y. J. (2012). Transformation of smart-card-based single-purpose e-micropayment scheme to multipurpose scheme: A case study. Expert Systems with Applications, 39(3), 2306-2313. https://doi.org/10.1016/j.eswa.2011.08.017

Trafimow, D. (2009). The Theory of Reasoned Action: A Case Study of Falsification in Psychology. Theory \& Psychology, 19(4), 501-518. https://doi.org/10.1177/0959354309336319

Verkijika, S. F. (2018). Factors influencing the adoption of mobile commerce applications in Cameroon. Telematics and Informatics, (September 2017), 0-1. https://doi.org/10.1016/j.tele.2018.04.012

Zhang, Y., Weng, Q., \& Zhu, N. (2018). The relationships between electronic banking adoption and its antecedents: A meta-analytic study of the role of national culture. International Journal of Information Management, 40(February), 76-87. https://doi.org/10.1016/j.ijinfomgt.2018.01.015 